\title{
The Repetition of Chunks in Korean Middle School English Textbooks
}

\author{
Jinkyong Lee ${ }^{1}$ \\ ${ }^{1}$ Department of English Education, College of Education, Catholic University of Daegu, Korea \\ Correspondence: Jinkyong Lee, Department of English Education, College of Education, Catholic University of \\ Daegu, Hayang, 712-702, Korea. E-mail: jinlee@cu.ac.kr
}

Received: July 21, 2015 Accepted: September 5, 2015 Online Published: September 8, 2015

doi:10.5539/elt.v8n10p60 URL: http://dx.doi.org/10.5539/elt.v8n10p60

\begin{abstract}
The current study aims to examine the use of chunks and the extent of repetition in Korean middle school English textbooks. Also, the number of chunks shared by three publishers is examined. To create the corpora, 9 textbooks from three publishers were filed and processed by Simple Concordance Program. The results showed that chunk expressions were repeated 3.6 times on average. Most collocations occurred only one to two times throughout the same series of textbooks. Fixed-expressions showed similar results to those of lexical expressions, while semi-fixed expressions were shown relatively higher frequency rate than the other chunks. Regarding the repetition of chunks, most chunks were reused over 2 or 3 units. The number of chunks shared by three publishers in common was not many. It can be inferred that there were no agreed criteria for the selection and repetition of chunks among the textbook writers. The national curriculum works as a guideline, but the process of selecting items seems to be highly subjective and conducted without the consideration of repetition rate.
\end{abstract}

Keywords: chunks, repetition rate, English textbooks, collocations, fixed-expressions, semi-fixed expressions

\section{Introduction}

In the era of globalization, the prevalence of English as a universal lingua franca today has advanced the interconnectivity for people across boundaries. The changing status of English language has affected the way that the language is learned and used. English is neither the language for English native speakers alone, nor can it be defined simply by British or American culture. The ability to communicate well in English is a highly regarded skill for higher education and better employment. In these situations, many blame the practice for Korean students' lack of English proficiency, even after they have studied English for years. In fact, the Korean Ministry of Education has made many efforts to improve the students' oral proficiency. As indicated by the recent Korean national curriculum guidelines, the main purpose of English education in Korea aims to help students develop English language skills to enable them to communicate effectively with foreigners on general everyday topics (Korean Ministry of Education, 2009).

However, in the context of EFL when English is not used frequently, it presents a challenge for Korean students achieving native-like fluency. The speaking process consists of three components: generating a preverbal message, putting this message into words, and articulating the generated utterance (Levelt, 1989). Compared to L1 speakers, L2 speakers encounter more problems in expressing their ideas using correct morphosyntactic forms, in finding correct words, and in articulating their utterances correctly and fluently.

Recent research on L2 development has paid attention to the role of chunks (Note 1) in the process of language production, especially in speaking (de Bot, 1992; Dechert, 1983; Nattinger \& DeCarrico, 1992; Pawley \& Syder, 1983; Stengers, Boers, House, \& Eyckmans, 2011; Taguchi, 2008). The studies have noticed the way in which L2 speakers rely on chunks or memorized sequences of language rather than generating novel utterances based on grammatical rules. Chunks are considered to reduce processing demands and promote oral fluency, because chunks are easy to remember and faster to retrieve and produce (Newell \& Rosenbloom, 1981). Reduced processing load might free up memory space for additional information like the appropriate response or planning of a wider discourse. 
Studies on the role of chunks in language acquisition and the development of productive skills are widely available; yet empirical findings in chunk learning in L2 instruction remain insufficient. Gatbonton \& Sagalowitz (2005) suggest the use of communicative drills in which learners repeatedly practice a sentence or a pattern driven by their own communicative needs. Stringer (1998) designs an activity in which students were asked to rehearse and memorize the phrases in dialogues. The results showed that features of speech disfluency, such as pauses or false starts, have significantly decreased. Repetitive use of chunks in the communicative context can improve the overall oral fluency.

The importance of repetition in acquisition of individual words has received a huge amount of attention, while only few studies to date have investigated the actual effect of repetition of chunks on L2 development. Since EFL learners are exposed to the limited target language input, research on the kinds of chunks and the usage frequency of chunks in textbooks can provide L2 teachers and textbook writers with useful insights about L2 learning and performance.

The interest on the repetitive presentation of chunks corresponds to the major principles of revised national curriculum of 2009 (Ministry of Education, Republic of Korea). The revised curriculum affirms the adoption of spiral curriculum in which content of a subject matter is revisited repeatedly at different levels of development. If English, as a subject matter, adopts this principle, English expressions or structures will be progressively revisited in more complex forms as students' proficiency level advances.

In addition, the national curriculum guidelines (the revised version of 2009) recommend the utilization of basic vocabulary list up to $80 \%$ in order to increase the use of authentic and useful words. As Schmitt (2008) claims, aspects of knowing a word, such as collocations and intuition of frequency, are difficult to teach, so learners should be given much more opportunities to repeatedly encounter vocabulary in a variety of contexts. Several researchers (Conzett, 2000; Gitsaki, 1999; Harwood, 2002; Lewis, 1997) have strongly recommended that chunks shall be recycled regularly and systematically in teaching materials for recognition and production purposes, helping learners easily integrate chunks into their mental lexicon.

In this context, the present study aims to examine types of chunks and the repetition or recycling of chunks in the textbooks following the revised Korean national curriculum guidelines. The following research questions are addressed in the study.

1). How many chunks of each type are found in Korea's middle school English textbooks?

2). How often are the chunks recycled throughout a whole series of textbooks?

3). How many chunks are used in common in textbooks from three publishers?

\section{Literature Review}

\subsection{Definition of Chunks}

As Firth (1957) points out, it is important to know the words that come with a word when you learn a certain word. Firth included the collocation in the meaning of 'a word.' In a similar vein, Sinclair (1991) claims that fluent language use is not based on creative construction, but on semi-preconstructed phrases. Likewise, Ellis (2001) argues that although it is possible for linguists to discover grammar rules in instances of language, language knowledge and language use can be accounted for by the storage of chunks of language in long-term memory, as well as by experience of the reoccurring likelihood of particular chunks with other chunks, without the need to refer to underlying rules. This viewpoint sees collocational knowledge as the essence of language knowledge.

There seems to be no refuting about the phenomenon of repetitive pattern of language use, although various terms are used. Chunks have been studied under many rubrics including, 'lexical phrases', 'formulas', 'routines', 'fixed expressions', and 'pre-fabricated patterns'. These approaches, which define the object of study in somewhat different terms by using different criteria and explanations for the identification of multi-word sequences, provide different perspectives on the use of multi-word sequences (Weinert, 1995).

In this study, chunks are adopted to refer the multi-word phrases. First of all, the term succinctly represents the processing advantages of the notion that word sequences are stored and retrieved as a whole from memory. It suits our purposes well, as it can also comprehend the structurally incomplete forms of sequences.

The present study has focused on the frequency and recurring patterns of 3 kinds of chunks: lexical collocations, fixed-expressions, and semi-fixed expressions. In order to classify chunks into 3 subcategories, previous studies 
on chunks have been carefully followed. Lexical collocations are word combinations where one word recurrently co-occurs with one or more other words as the only one or one of few possible lexical choices. Typical examples of lexical collocations include: reach a verdict, make an impression, and warm regards (M. Benson, E. Benson, \& Ilson, 1986).

Fixed-expressions are word groups used in a particular context that often no substitution is allowed in any of their components. These are used as longer institutionalized attached with social functions or pragmatic meanings. Examples include What's up? Take it easy, and No problem (Nattinger \& DeCarrico, 1992).

Semi-fixed expressions are similar to fixed-expressions, except they allow replacement in at least one or more of their component chosen from a relatively small group of words. Examples include Let's talk about $\sim$ I think $\sim$, and I'm going to $\sim$ (Hsu, 2008).

\subsection{Role of Chunks in Language Learning}

There have been two conflicting views as to the relationship of chunks to language acquisition. Krashen and Scarcella (1978) admit the role of chunks in the process of language production. Chunks are just an outperforming strategy, according to Krashen and Scarcella, as they deny the facilitating role of chunks in L2 development. In contrast, other researchers (Myles, Hooper, \& Mitchell, 1998; Lee, 2002; Perera, 2001; Wong-Fillmore, 1976) have argued that chunks get analyzed, first partially and then fully and eventually lead to syntactic rules. From cognitive perspectives, Ellis (1996) contends that language learning is essentially the learning of formulaic sequences and their interpretations.

Wray and Perkins (2000) take the middle path by proposing a balance between creativity and formulaicity. Their view is that communicative language processing can be achieved by the establishment of a suitable balance between creative and holistic processes. The advantage of the creative system is the freedom to produce or decode the unexpected, whereas the advantage of the holistic system is economy of effort when dealing with the expected (Wray, 2002, p. 19). They assert on the role of chunks in language acquisition, but denied the limited view of one strategy only for production.

Unlike the role of chunks in the language acquisition process, usefulness of chunks in the language learning is generally recognized. It has been argued that adopting a chunk approach to $\mathrm{L} 2$ teaching seems relevant for at least three main reasons: (a) chunks are ubiquitous in language; (b) the use of chunks has been shown to be a marker of proficiency in an L2; and (c) studies have demonstrated that L2 language learners find chunks particularly challenging, as it is impossible for them to use the innate native intuition associated with chunks (Granger, 1998; Howarth, 1998; Nesselhauf, 2003).

Boers, Eyckmans, Kappel, Stengers, and Demecheleer (2006) also provide three benefits for a command of chunks in L2. First, mastery of chunks can help learners come across as native-like. In other words, learners apply the idiom principle first before the open choice principle when we process language (Sinclair, 1987). Second, chunks are believed to be retrieved from memory holistically, as pre-fabricated, ready-made units, they can facilitate language fluency under real-time conditions. Third, chunks may help learners reach a degree of linguistic accuracy. According to Skehan (1998), learners take advantage of chunks to ease processing problems, to buy processing time while other computation proceeds. This enables learners to plan ahead for the content of what they are going to say, so their linguistic accuracy can be increased.

In short, various research efforts have been devoted to formulaic expressions or chunks over the past decades in the domain of L2 learning. It is too complex to draw simple conclusions about the role of chunks in the language acquisition. Nevertheless, there appears to be a general consensus that L2 performance is progressively aided and enhanced by chunks.

\subsection{Chunks in English Textbooks}

Although chunks are believed to perform a crucial role in L2 learners' language learning process, it is difficult to say with conviction on how they operate during the process. After reviewing experimental and intervention studies published since 2004 on formulaic sequences in a second language, Boers and Lindstromberg (2012) categorize pedagogical treatments for helping L2 learners' make better progress in their mastery of chunks into three groups: (a) drawing learners' attention to chunks when encountered, (b) stimulating lookups in dictionaries and the use of corpus tools, and (c) helping learners commit particular chunks to memory. According to Boers and Lindstromberg, studies focusing on the ways of directing learners' attention to ubiquity of chunks and enhancing awareness of formulaicity fall on (a). Pedagogical interventions that group (b) utilizes are using 
dictionaries by which learners verify the meaning and increase the autonomy. Boers and Lindstromberg assign the category (c) to the studies that use various methods like a recall test, contrastive analysis, or sound repetition as a means of stimulating retention of chunks. Nonetheless, one fundamental oversight, probably due to the paucity of research, in their extensive review on chunks in L2 learning and teaching is the appropriateness of textbooks used in the classroom.

Textbooks are perhaps the most powerful device in language teaching (Littlejohn, 1998, p. 190). They have been considered as the basis for much of the language classroom teaching. In an EFL context, particularly, textbooks may constitute the primary source of language input that learners receive and provide the basis for much of the language practice taking place in the classroom (Tomlinson, 2011). Considering the fact that the materials often dictate the teaching method, one cannot stress enough the importance of textbooks in English teaching, as textbooks solidify students' competence in English language use (Moon, 1997). Several studies (Ellis, Simpson-Vlach, \& Maynard, 2008; Laufer \& Waldman, 2011; Serrano, Stengers, \& Housen, 2015) suggest that there are vast differences in the use of chunks between native speakers and EFL learners, even if they are at the advanced level. The differences could be explained from various perspectives; however, close examination on the selection and alignment of chunks in textbooks is needed to reduce the gap.

As mentioned above, studies investigating textbooks to discuss the acquisition of chunks are not many. Gitsaki (1999) shows the influence of textbooks on students' learning by examining the correlation between the students' collocational knowledge and collocation patterns in the textbooks. The finding suggests a positive correlation that the more a certain collocation pattern appears in a textbook, the greater number of and more accurate the collocations of that pattern the students produce.

Wang and Good (2007) examine repetitions of collocations used in Taiwanese high school textbooks, and the results show that collocations are repeated from 3 to 5 times on average and most collocations are repeated only 1 to 5 times through the whole series of textbooks. The study concludes that textbook writers should make collocations more salient by recycling them to promote the acquisition of collocations.

Hsu (2008) investigates multiword lexical units presented in three contemporary ESL/EFL textbooks published between 2003 and 2005. Hsu points out the inconsistency in the criteria selecting and presenting the chunks among the textbooks. Hsu recommends classroom teachers to be aware of the role of chunks in language learning, rather than wasting time on learning chunks of less value.

In addition, school textbooks for L2 learners show a weakening stock of chunks (Wray, 2012). Commercially published textbooks have been quick to incorporate the pedagogic value of chunks or multiword lexical items into their materials to satisfy consumers and to keep up with the latest in linguistic fashion. (Koprowski, 2005). One major problem of this practice is the arbitrary selection of chunks for a textbook.

Recent literature conducted in Korea has mostly focused on collocations among the various types of chunks. Studies have looked into other types of chunks are concerned with the effects of learning chunks on English proficiency or development of vocabulary competence. Many studies using textbook corpora have been published lately. The majority of them explore the frequency and distribution of individual words or whole vocabulary as a wordlist (H. Y. Kim, 2009; J. R. Kim, 2009). These studies compared the usage and frequency of words with the native speaker corpora, while evaluating the appropriateness of wordlist presented in the Korean national curriculum. A few previous studies have analyzed the usage of collocations in the textbooks $(\mathrm{H}$. Y. Choi, \& Y. V. Chon, 2012; N. B.Kim, 2004).

Unlike other literature, this study emphasizes the frequency and repetition rate of chunks. In other words, the study questions not only how many chunks are found, but also how often chunks are recycled after they were first introduced. In addition, the study interrogates the much under researched field of fixed and semi-fixed expressions, which are specified as communicative function sentences in the Korean national curriculum.

\section{Method}

\subsection{English Textbooks Comprising the Corpus}

To create the corpus for the study, we randomly selected the textbooks, which were written following the 2009 revision of national curriculum. Nine volumes of textbooks from three publishers, ranging from the first year to third year of the middle school, formed three corpora. Since chunks may appear in any part of the textbook, either the reading section or non-reading section, such as comprehension check, listening script, grammar activities, and others, every part of each lesson was analyzed. 
Table 1 displays the details on the textbooks. The differences in the number of units and word types exist among the publishers. BS textbooks show the most number of word types, whereas DS textbooks show the least word types with all the most number of unit. Regarding the number of chunks, BS textbooks show the highest frequency, but $\mathrm{CJ}$ textbooks show the highest type/ token ratio.

Table 1. Details of textbooks used for corpus analysis

\begin{tabular}{lllllll}
\hline Publishers & No. of unit & $\begin{array}{l}\text { No. of word } \\
\text { types }\end{array}$ & & No. of words & $\begin{array}{l}\text { Total no. of } \\
\text { chunks } \\
\text { Type/Token }\end{array}$ & $\begin{array}{l}\text { No. of chunks } \\
\text { per unit } \\
\text { Type/Token }\end{array}$ \\
\hline Bisang(BS) & 30 & 2676 & 27120 & $378 / 993$ & $12.6 / 33.1$ \\
Chunjae(CJ) & 30 & 2362 & 31485 & $329 / 1579$ & $32.9 / 52.6$ \\
Doosan(DS) & 32 & 2140 & 25576 & $280 / 1010$ & $8.75 / 31.56$ \\
\hline
\end{tabular}

(Data source: Middle School English 1, 2, 3 by Bisang Publishing Company (2013), Middle School English 1, 2, 3 by Chunjae Publishing Company (2013), Middle School English 1, 2, 3 by Doosan Publishing Company (2013).

\subsection{Data Analysis Procedure}

First, three types of chunks were singled out manually, and listed for analysis. As for the lexical collocation type, only verb-noun collocations were included in the analysis. Among the various types of collocations, verb-noun lexical collocations were found to be the most difficult type for Korean EFL learners (Park, 2003). In addition, verb-noun collocations lead a more central role in language acquisition process than others, such as adverb-adjective collocations, because verb-noun combinations predominantly form the basic structures of sentences. Therefore, verb-noun collocations were one of the primary focuses of the present study.

Fixed expressions are defined as set phrases which allow no replacement in any of their components, and this irreplaceability feature was used as a criterion for identifying fixed expressions. Semi-expressions are similar to fixed expressions, except they allow replacement.

These three types of chunks were made into files for analysis. Simple Concordance Program 4.0.9 (Note 2) was employed to retrieve all the chunks in the three corpora. This concordance program can retrieve items specified by the user from a large amount of data. It shows the total number of occurrences and displays them in lines of context. Then each instance for each category was counted and calculated as a percentage of the total amount of instances. The extracted chunks were traced manually one by one to examine the distribution of chunks over the same series. Many of them appeared only one or two times throughout the whole series, so the chunks used more than four times were counted to reveal the recycling aspects.

\section{Results and Discussions}

The results of the corpus analysis are presented according to the chunk types, rather than the order of research questions, because describing the frequency and the range of frequency altogether provide the complete picture of the use of each chunk type.

\subsection{Verb-noun Collocations}

Findings reveal that the more collocation types in a series, the less the collocations tend to be recycled on average. Table 2 displays the series totals, volume means for the different verb-noun collocations found in the textbooks. From the table, one verb-noun collocation was used about twice in the whole series, although there were differences among three publishers. BS textbooks showed the most variety of collocations, but they were used less than the expressions in other textbooks. CJ is somewhat more likely to recycle verb-noun collocations than the other two. The mean number of occurrences of collocation types in 9 textbooks is 2.1, which is far from being sufficient for learners to notice the expressions. 
Table 2. Frequency of verb-noun collocations by token and type

\begin{tabular}{lllll}
\hline $\begin{array}{l}\text { Publishers } \\
\text { Tokens/Types }\end{array}$ & Year & 2nd & 3rd & Total \\
\cline { 2 - 3 } & 1st & & $138 / 77$ & $332 / 220$ \\
\hline BS & $79 / 64$ & $115 / 79$ & 1.7 & 1.5 \\
Token /Type & 1.2 & 1.4 & & $363 / 139$ \\
CJ & & & $106 / 35$ & 2.6 \\
Token /Type & $126 / 60$ & $131 / 44$ & 3.0 & $328 / 131$ \\
Mean & 2.1 & 2.9 & $108 / 38$ & 2.5 \\
DS & & $132 / 49$ & 2.8 & $1023 / 490$ \\
Token /Type & $88 / 44$ & 2.6 & & 2.1 \\
Mean & 2.0 & & & \\
& & & & \\
\end{tabular}

Note. The mean occurrences per type are calculated by dividing the total number of tokens into the total number of types; i.e., tokens/types.

Many studies have shown that the use of collocations is problematic for L2 learners. Bahns and Eldaw (1993) report that German English learners produced more than twice as many errors in their translations of collocates as in their translation of single lexical items. Considering that the assigned task is a written task, the errors are probably related to the lack of knowledge, rather than the lack of control. They argue that learners' knowledge of collocations is not on a par with their knowledge of general vocabulary. In this respect, in order to increase the knowledge of collocations without increasing burden on memory capacity, collocations made of general words should be repeatedly presented. Learning more words is not always necessarily about learning new words; instead it is often learning familiar words in new combinations.

Table 3. Frequency of verb-noun collocation types with examples

\begin{tabular}{lllll}
\hline Frequency & BS & CJ & DS & Total \\
\hline 1 & $154(70 \%)$ & $67(48.2 \%)$ & $66(50.3 \%)$ & 287 \\
& run a camp & tell a joke & answer the phone & $(58.5 \%)$ \\
$2 \sim 3$ & $50(22.7 \%)$ & $44(31.6 \%)$ & $37(28.2 \%)$ & 131 \\
& make a mistake & set the table & make a face & $(26.7 \%)$ \\
$4 \sim 6$ & $14(6.3 \%)$ & $16(11.5 \%)$ & $16(12.2 \%)$ & 46 \\
& lose weight & see a doctor & make a mistake & $(9.3 \%)$ \\
$7 \sim 9$ & $2(0.9 \%)$ & $7(5.0 \%)$ & $6(4.5 \%)$ & 15 \\
& join a club & do homework & go camping & $(3.0 \%)$ \\
$10+$ & 0 & $5(3.5 \%)$ & $6(4.5 \%)$ & 11 \\
& & ride a bike & play basketball & $(2.2 \%)$ \\
Total & $220(100 \%)$ & $139(100 \%)$ & $131(100 \%)$ & 490 \\
& & & & $(100 \%)$ \\
\hline
\end{tabular}


Table 3 shows that over half of the collocations occur only once and $26.7 \%$ of collocations occur two to three times. In comparison with the large number of these low frequency collocations, collocations with relatively high occurrences (4 times and more) are BS: 7.2\%; CJ: 20\%; DS: $14.5 \%$, respectively. This explains the low ratio of token/type in Table 2 . The collocations with high frequency were mostly relevant to daily activities of teenagers, for instance, do homework, ride a bike and play basketball.

The mean number of occurrences per textbook series is only one way to look at the repetitive use of chunks. Repetitive occurrence of a chunk in a unit may be conducive to the acquisition of it, but in addition to this, the chunk should keep recurring throughout the series of textbooks before settling into long-term memory. In other words, Table 3 shows the total number of occurrence of a collocation expression throughout the series of textbooks without the distribution information of an expression. Thus, the number of lesson unit in which a chunk can be found was further examined to reveal the frequency range of a collocation.

Table 4. Frequency ranges of verb-noun collocations with examples

\begin{tabular}{|c|c|c|c|c|c|c|}
\hline & 1unit & $2 \sim 3$ units & $4 \sim 5$ units & $6 \sim 7$ units & 8 units + & Total \\
\hline BS & & $\begin{array}{l}5(31.3 \%) \\
\text { make money }\end{array}$ & $\begin{array}{l}10(62.5 \%) \\
\text { make a friend }\end{array}$ & $\begin{array}{l}1(6.2 \%) \\
\text { watch a movie }\end{array}$ & & $\begin{array}{l}16 \\
(100 \%)\end{array}$ \\
\hline CJ & $\begin{array}{l}2(7.2 \%) \\
\text { mop the } \\
\text { floor, } \\
\text { make a } \\
\text { joke }\end{array}$ & $\begin{array}{l}10(35.7 \%) \\
\text { do homework }\end{array}$ & $\begin{array}{l}10(35.7 \%) \\
\text { go shopping }\end{array}$ & $\begin{array}{l}3(10.7 \%) \\
\text { have a party }\end{array}$ & $\begin{array}{l}3(10.7 \%) \\
\text { play soccer }\end{array}$ & $\begin{array}{l}28 \\
(100 \%)\end{array}$ \\
\hline DS & & $\begin{array}{l}10(35.7 \%) \\
\text { have classes }\end{array}$ & $\begin{array}{l}13(46.4 \%) \\
\text { do volunteer } \\
\text { work }\end{array}$ & $\begin{array}{l}4(14.3 \%) \\
\text { take a picture }\end{array}$ & $\begin{array}{l}1(3.6 \%) \\
\text { watch TV }\end{array}$ & $\begin{array}{l}28 \\
(100 \%)\end{array}$ \\
\hline Total & 2 & 25 & 33 & 8 & 4 & 72 \\
\hline
\end{tabular}

Table 4 shows the results of examination on the distribution of collocation expressions that occurred at least four times. For example, mop the floor and make a joke occurred 4 times, but in only one unit, while do homework occurred in 2 or 3 units and there were 10 collocation expressions showing the same pattern of distribution. One more notable aspect of Table 4 is the number of collocation expressions, which occurred at least 4 times is insignificant considering the total number of collocation types. The verb play was used the most with nouns referring sports or musical instruments, and watch a movie or TV program ranked the second.

As seen from Table 4, only 12 verb-noun collocations were shown in over 6 units. Most of the collocations were used in 2 to 5 units and many of them used the delexicalized verbs, for example, do, have or make as collocates. Selected examples show that there are not many common items. Table 5 summarizes the verb-noun collocations found in common in 9 textbooks. Forty four types were commonly used, accounting for $11.3 \%$ of the total collocation types. 
Table 5. Verb-noun collocations used in common in the textbooks from three publishers

\begin{tabular}{ll}
\hline Verb-noun collocations used in common & \\
\hline celebrate holidays/birthdays & save a life/energy/money \\
do homework & see a doctor \\
enter a contest/competition & set the table \\
go camping/fishing/shopping & solve the problem \\
have a cold/party & spend money \\
join a club & take a bus/pictures \\
keep a diary & take time \\
leave a message & walk a dog \\
lose weight/a game/contest & watch a movie/TV \\
make a mistake/friends & water the plant \\
pass the exam & win a medal/prize \\
play badminton/basketball/guitar/ & write a story \\
soccer/piano/violin/games & ride a bike \\
\hline
\end{tabular}

\subsection{Fixed Expressions}

Fixed expressions are considered to play an important role in both oral and written language production and language learning. Pawley and Syder (1983; p. 191) argue that fluent and idiomatic control of a language rests to a considerable extent on knowledge of a body of "sentence stems," which are institutionalized or lexicalized. Table 6 shows the number of fixed expressions selected by the criterion mentioned above, irreplaceability of the components. Each expression was processed by using the Simple Concordance Program in order to find out the number of occurrence in the textbooks.

Table 6. Frequency of fixed expressions by type and token

\begin{tabular}{lllll}
\hline & BS & CJ & DS & Total \\
\hline Type/token & $117 / 380$ & $140 / 608$ & $106 / 394$ & $363 / 1382$ \\
Mean & 3.25 & 4.34 & 3.72 & 3.81 \\
\hline
\end{tabular}

As shown in Table 6, one fixed expression was used 3.81 times on average in the textbooks. Textbooks from CJ showed the highest ratio of type to token, while BS textbooks had the lowest ratio. Table 7 shows the frequency of occurrence of fixed expressions by the publishers with selected examples. 
Table 7. Frequency of Fixed expression types with examples

\begin{tabular}{llll}
\hline Frequency & BS & CJ & DS \\
\hline \multirow{2}{*}{1} & $33(28.2 \%)$ & $42(30.0 \%)$ & $23(21.7 \%)$ \\
& Good for you! & Fine with me. & Good point. \\
$2 \sim 3$ & $42(35.9 \%)$ & $30(21.4 \%)$ & $38(35.8 \%)$ \\
& How's it going? & No way! & Come on! \\
$4 \sim 6$ & $32(27.4 \%)$ & $31(22.1 \%)$ & $30(28.4 \%)$ \\
& Of course & Take care. & Not at all \\
$7 \sim 9$ & $8(6.8 \%)$ & $21(15 \%)$ & $12(11.3 \%)$ \\
& That's a good idea. & What's wrong? & What's wrong? \\
$10+$ & $2(1.7 \%)$ & $16(11.4 \%)$ & $3(2.8 \%)$ \\
\multirow{2}{*}{ Total } & I'd like to & How about you? & Of course \\
\hline
\end{tabular}

Most of the fixed expressions were used less than 7 times through the entire series of textbooks. Expressions used more than 10 times were small in number except for the cases of ones from CJ textbooks. In the textbooks from CJ, several fixed expressions, including How about you? What's the matter, or It's surprising occurred more than 10 times, especially the expression I see occurred 25 times.

However, encountering an expression intensively in a couple of unit is insufficient for learners to absorb the fixed expression. It is necessary to recycle the expression throughout the entire series of three textbooks. Table 8 shows that low percentage of fixed expressions occurred in more than 3 units. The data show that most fixed expressions occurred in two to three units or less. In particular, $69.3 \%$ of fixed expressions occurred in only one unit in CJ textbooks.

Table 8. Frequency ranges of fixed expressions with examples

\begin{tabular}{|c|c|c|c|c|c|c|}
\hline & 1unit & $2 \sim 3$ units & $4 \sim 5$ units & $6 \sim 7$ units & $8+$ units & Total \\
\hline \multirow[b]{2}{*}{ BS } & $59(50.5 \%)$ & $38(32.5 \%)$ & $10(8.5 \%)$ & $9(7.7 \%)$ & $1(0.8 \%)$ & \multirow{2}{*}{$\begin{array}{l}117 \\
(100 \%)\end{array}$} \\
\hline & How about you? & My pleasure. & I'm sorry. & Don't worry. & I see. & \\
\hline \multirow[b]{2}{*}{ CJ } & \multirow{2}{*}{$\begin{array}{l}97(69.3 \%) \\
\text { Are you sure? }\end{array}$} & \multirow{2}{*}{$\begin{array}{l}30(21.4 \%) \\
\text { Here it is. }\end{array}$} & $8(5.8 \%)$ & $3(2.1 \%)$ & $2(1.4 \%)$ & \multirow{2}{*}{$\begin{array}{l}140 \\
(100 \%)\end{array}$} \\
\hline & & & No problem & You're right. & I see. & \\
\hline \multirow[b]{2}{*}{ DS } & $40(37.8 \%)$ & $40(37.8 \%)$ & $12(11.3 \%)$ & $9(8.4 \%)$ & $5(4.7)$ & \multirow{2}{*}{$\begin{array}{l}106 \\
(100 \%)\end{array}$} \\
\hline & $\begin{array}{l}\text { Long time no } \\
\text { see. }\end{array}$ & Let me see. & Sounds great. & I'm not sure. & I'd love to. & \\
\hline
\end{tabular}

Judging from the data we have seen, fixed expressions were not properly recycled as in the case of collocations. Most fixed expressions were reused in one to three units and a few expressions were reused in several units. The question then arose as to the existence of the criteria for occurrence of expressions. Selected examples listed in Table 8 do not seem to provide the positive answer to the question. The issue of how many collocation should be taught has been raised in several earlier studies (Bahns \& Eldaw, 1993; Hill, 2000; Nesselhauf, 2003), but in the 
case of fixed expressions, the issue was hardly dealt with. It should be checked if narrow range expressions may have been more common than wide range expressions. Also, there should be criteria by which chunks can be assessed and incorporated in textbooks. The following Table 9 shows the fixed expressions shared by textbooks from three publishers. 41 items, which represents $11.3 \%$ of total fixed expression types, were used in common.

Table 9. Fixed expressions shared in common by the textbooks from three publishers

Fixed expressions used in common

Are you sure?

Sounds great

By the way

Thank you.

Don't worry.

Thanks a lot.

Excuse me.

That sounds (like) fun

Good morning.

That's a good idea.

Here you are.

That's great.

How about you?

That's interesting.

How interesting.

That's right.

How's it going?

That's too bad

I agree.

Watch out.

I don't agree.

What about you?

I don't know.

What do you think?

I see.

What happened?

I'm home.

What's up?

I'm sorry.

What's wrong?

I'm sorry to hear that.

What's your name?

Let me see

Why not?

No problem

Why the long face?

No, thanks.

Yes, please.

Not at all

You are right

Of course

Out of 363 types, only 41 types were used in common by 3 publishers in the textbooks. It should be acknowledged that there needs to be criteria which measure the pedagogical priority of chunks in order to help students learn the essential chunks for effective communication.

\subsection{Semi-fixed Expressions}

Semi-fixed expressions are chunks that allow replacement in at least one or more of their components chosen from a relatively small group of words. In the present study, the chunks presented as one of lesson objectives in each unit were examined to delimit the number of types, since the main objective of this study was to examine the repetition of chunks, rather than the frequency of chunks itself. 
Table 10. Frequency of semi-fixed expressions by type and token

\begin{tabular}{lllll}
\hline & BS & CJ & DS & Total \\
\hline Type/token & $41 / 281$ & $50 / 608$ & $43 / 288$ & $134 / 1177$ \\
Mean & 6.85 & 12.16 & 6.7 & 8.78 \\
\hline
\end{tabular}

In comparison with the verb-noun collocations and fixed expressions, semi-fixed expressions were used more frequently than the other two types of chunks as seen in Table 10. This could be explained by the fact that these semi-fixed expressions were presented as learning objectives, performing particular communicative functions. Pre-established learning objectives might make the textbook writers purposely adopt certain words in writing. As a result, semi-fixed expressions could have been intentionally employed more. Certainly, the flexibility of replacing some components also helps increase the frequency of use. However, the number of semi-fixed expressions per publisher varied, because some communicative functions were presented in the form of fixed expressions.

Table 11. Frequency of Semi-fixed expression types with examples

\begin{tabular}{llll}
\hline Frequency & BS & CJ & DS \\
\hline \multirow{2}{*}{$2 \sim 4$} & $20(48.7 \%)$ & $2(4 \%)$ & $21(48.8 \%)$ \\
& Do you mean $\sim$ & How often do you $?$ \\
$5 \sim 7$ & $12((29.3 \%)$ & I'm against $~$ & $11(25.6 \%)$ \\
& Have you heard of $\sim$ ? & $14(28 \%)$ & Do you mind if $\sim$ \\
$8 \sim 11$ & $4(9.8 \%)$ & $14(28 \%)$ & $6(13.9 \%)$ \\
& Ithink that $\sim$ & What do you think of $\sim$ ? & Thank you for $\sim$ \\
$12 \sim 15$ & $1(2.4 \%)$ & $11(22 \%)$ & $2(4.7 \%)$ \\
& I'm going to $\sim$ & May I ? \\
+16 & $4(9.8 \%)$ & What kind of $\sim ?$ & $3(7 \%)$ \\
& I want to $~$ & $9(18 \%)$ & I'm going to $~$ \\
Total & $41(100 \%)$ & Let me & $43(100 \%)$ \\
\hline
\end{tabular}

Among the publishers, $\mathrm{CJ}$ made the most of semi-fixed expressions as seen in Table 11. Only 2 expressions were used two to four times, and the others were used at least 5 times. On the other hand, in BS and DS textbooks, most of the semi-expressions were recycled two to seven times throughout the whole series. As discussed above, the mean number of occurrence is only one way to analyze the data. In addition to this, frequency ranges for semi-fixed expressions were examined.

Table 12 shows that high number of semi-fixed expressions occurred in less than four units. Especially, CJ textbooks, which showed the highest mean frequency, display this tendency also. In other words, the highest mean frequency does not guarantee the wide distribution of the expressions. Semi-fixed expressions were intensively recycled just in a couple of units. Based on the data, it is evident that the textbooks writers were unaware of the issue about repetitive occurrence of chunks. As Criado (2009) rightly points out, what matters in chunk acquisition is the amount of lexical information entering and consolidating in long-term memory. Long-term memory is activated and strengthened mainly through rehearsal or repetitive practice and activation. From the perspective of efficiency in chunk acquisition, chunks need to be recycled with consistency at a certain interval. 
Table 12. Frequency ranges of semi-fixed expressions with examples

\begin{tabular}{|c|c|c|c|c|c|c|}
\hline & 1unit & $2 \sim 3$ units & $4 \sim 5$ units & $6 \sim 7$ units & $8+$ units & Total \\
\hline \multirow[b]{2}{*}{$\mathrm{BS}$} & $22(53.7 \%)$ & $11(26.8 \%)$ & $3(7.3 \%)$ & $2(4.9 \%)$ & $3(7.3 \%)$ & 41 \\
\hline & $\begin{array}{l}\text { I wish } \\
\text { I could }\end{array}$ & $\begin{array}{l}\text { It's important } \\
\text { to } ~\end{array}$ & I'm sure & I'm going to & I want to & $(100 \%)$ \\
\hline \multirow{2}{*}{$\mathrm{CJ}$} & $20(40 \%)$ & $20(40 \%)$ & $3(6 \%)$ & $6(12 \%)$ & $1(2 \%)$ & 50 \\
\hline & May I speak to & better than & Why don't we & You must & Can you & $(100 \%)$ \\
\hline \multirow{2}{*}{ DS } & $23(53.5 \%)$ & $13(30.2 \%)$ & $4(9.3 \%)$ & $1(2.3 \%)$ & $2(4.7 \%)$ & 43 \\
\hline & $\begin{array}{l}\text { What do you } \\
\text { think of }\end{array}$ & I'm thinking of & Thank you for & May $I \sim$ & I think & $(100 \%)$ \\
\hline
\end{tabular}

Regarding the expressions, which were found in common among the publishers, only four items were observed, as seen in Table 13. This accounts for 3\% of all the semi-fixed expressions. It does not mean that only four semi-fixed expressions were used in common, rather only four expressions were presented as lesson objectives. This small number of common elements reveals the necessity of agreed criteria for semi-fixed expressions.

The national curriculum provides the word list and lists of communicative functions with examples. The list functions as a guide or reference for creating textbooks, rather than a mandatory requirement for selecting and sequencing of the items. In the revised version of 2009 national curriculum, 122 communicative functions are presented with 460 example sentences, which is composed of 220 semi-fixed expressions and 240 fixed expressions. Considering the number of examples of communicative functions, it is unlikely to adopt the same semi-fixed expressions more than four times. This small number of expressions occurred in common indicates the lack of criteria for presentation pattern of semi-fixed expressions.

Table 13. Semi-fixed expressions used in common

\begin{tabular}{ll}
\hline Do you remember $\sim$ & I can't wait to $\sim$ \\
\hline I'm going to $\sim$ & You'd better $\sim$ \\
\hline
\end{tabular}

\section{Conclusion}

The present study examined how many chunks occurred and to what extent they were recycled in the Korean middle school English textbooks. Verb-noun collocations, fixed expressions, and semi-fixed expressions were defined to be categorized and processed by the SCP 4.09.

The frequency results show that collocations occurring the most among the three types of chunks. Although one type of collocation was examined, collocation expressions were used a lot, and then the fixed expressions were followed by semi-fixed expressions.

The repetition results showed that most collocations occurred no more than in 5 units out of 30 or 32 units. Four collocations were recycled more than in 8 units. This indicates that many collocations were used intensively in the unit, where they were introduced first, and then seldom repeated across other units.

The disregard for the distribution of items was found in the cases of other two types of chunks as well. Fixed expressions and semi-fixed expressions were also not recycled adequately after they were introduced for the first time. The lack of detailed pre-planning or guidelines may account for the low frequency of repetitions found in this study.

It is understandable that not all the chunks have the same pedagogical value, and every chunk cannot be recycled in the same degree. However, the question is whether there were criteria for the selection and repetition of chunks. As Koprowski (2005) argues, while material writers enthusiastic about adding chunks to the syllabus, 
the process of selecting items has been highly subjective and conducted without reference to corpus data. The challenge exists in how to choose useful and appropriate chunks for the students from an enormous number of chunks available in English. Since the printed words have the power to authenticate themselves, the process of chunk selection should be based on both empirical research and theory.

The lack of principles underlying selecting and offering chunks has to do with the small number of chunks used in common in the three textbooks. This lack of consensus among the textbook writers suggests the necessity of further research into the pedagogical value of lexical chunks. Although the term, pedagogical value could sound vague, objective criteria should be established and applied in the process of textbook writing. If frequency and range are deemed as important criteria, lexical chunks should be assessed and specified first by these criteria. After that, chunks could be selected and graded for the maximum pedagogical value.

It is not enough to offer a lot of chunks in the textbook. From the perspective of students, all chunks in the textbooks may be seen as holding equal pedagogic value. It is crucial and necessary to inquire how the learning of chunks can be improved, as well as which ones should be taught. Providing useful chunks with opportunities for using them repeatedly is an obvious answer to the question. Learning and using lexical chunks in communicative situations will help the learners achieve fluency in production skills.

The present study has revealed the aspects of use of chunks; yet there were no criteria by which pedagogical value of chunks could be assessed. As noted by Wang and Good (2007), deficiencies in the textbook can be translated into deficiencies in teaching and learning.

Studies on pedagogical value of chunks are needed, while, at the same time, an effort should be made to incorporate the chunks into the textbook more systematically. Utilizing repetition of chucks will contribute significantly towards improving students' English proficiency.

\section{Acknowledgments}

This work was supported by the National Research Foundation of Korea Grant funded by the Korean Government (NRF-2013S1A5A2A01019246).

\section{References}

Bahns, J., \& Eldaw, M. (1993). Should we teach EFL students collocations? System, 21(1), 101-14. http://dx.doi.org/10.1016/0346-251X(93)90010-E

Benson, M., Benson, E., \& Ilson, R. (1986). The BBI combinatory dictionary of English: A guide to word combinations. Amsterdam: John Benjamins. http://dx.doi.org/10.1075/z.bbi1(1st)

Boers, F., Eyckmans, J., Kappel, J., Stengers, H., \& Demecheleer, M. (2006). Formulaic sequences and perceived oral proficiency: Putting a lexical approach to the test. Language Teaching Research, 10(3), 245-261. http://dx.doi.org/10.1191/13621688061r195oa

Boers, F., Lindstromberg, S. (2012). Experimental and intervention studies on formulaic sequences in a second language. Annual Review of Applied Linguistics, 32, 83-110. http://dx.doi.org/10.1017/S0267190512000050

Choi, H. Y., \& Chon, Y. V. (2012). A corpus-based analysis of collocations in tenth-grade high school English textbooks. Multimedia Assisted Language Learning, 15(2), 41-73.

Conzett, J. (2000). Integrating collocation into a reading and writing course. In M. Lewis (Ed.), Teaching collocation: Further developments in the lexical approach (pp. 70-87). Hove, England: Language Teaching Publications.

Criado, R. (2009). The distribution of the lexical components in ELT coursebooks and its suitability for vocabulary acquisition from a cognitive perspective: A case study. International Journal of English Studies, Special issue, 39-60.

De Bot, K. (1992). A bilingual production model: Levelt's speaking model adapted. Applied Linguistics, 13(1), $1-24$.

Dechert, H. (1983). How a story is done in a second language. In C. Faerch, \& G. Kasper (Eds.), Strategies in interlanguage communication (pp. 175-95). London: Longman.

Ellis, N. (1996). Sequencing in SLA: Phonological memory, chunking, and points of order. Studies in Second 
Language Acquisition, 18, 91-126. http://dx.doi.org/10.1017/S0272263100014698

Ellis, N. (2001). Memory for language. In P. Robinson (Ed.), Cognition and second language instruction (pp 33-52), Cambridge: Cambridge University Press. http://dx.doi.org/10.1017/CBO9781139524780.004

Ellis, N., Simpson-Vlach, R., \& Maynard, C. (2008). Formulaic language in native and second language speakers: Psycholinguistics, corpus linguistics, and TESOL. TESOL Quarterly, 42(3), 375-396.

Fillmore, W. (1976). The second time around: Cognitive and social strategies in second language acquisition. Unpublished doctoral dissertation. Standford University.

Firth, R. (1957). Papers in linguistics 1934-1951. Oxford: Oxford University Press.

Gatbonton, E., \& Sagalowitz, N. (2005). Rethinking communicative language teaching: A focus on access to fluency. Canadian Modern Language Journal, 61, 325-353. http://dx.doi.org/10.3138/cmlr.61.3.325

Gitsaki, C. (1999). Second language lexical acquisition: A study of the development of collocational knowledge. San Francisco: International Scholars Publications.

Granger, S. (1998). Prefabricated patterns in advanced EFL writing: collocation and formulae. In P. Cowie (Ed.), Phraseology: theory, analysis, and applications (pp. 145-160). Oxford: Oxford University Press.

Harwood, N. (2002). Taking a lexical approach to teaching: Principles and problems. International Journal of Applied Linguistics, 12(2), 139-155. http://dx.doi.org/ 10.1111/1473-4192.00028

Hill, J. (2000). Revising priorities: From grammatical failure to collocational success. In M. Lewis (Ed.), Teaching collocation: Further developments in the lexical approach (pp. 47-69). Hove, England: Language Teaching Publications

Howarth, P. (1998). Phraseology and second language proficiency. Applied Linguistics, 19(1), 24-44. http://dx.doi.org/10.1093/applin/19.1.24

Hsu, J. (2008). Role of the multi-word lexical units in current EFL/ESL textbooks. US-China Foreign Language, $6(7), 27-39$.

Kim, H. Y. (2009). Vocabulary selection and modification in English textbook production. Foreign language education, 16(1). 101-121.

Kim, J. R. (2009). A study of basic vocabulary for integrated English education: Building ECI learners' dictionary. Multimedia Assisted Language Learning, 12(2), 163-185.

Kim, N. B. (2004). A collocational analysis of Korean high school English textbooks and suggestions for collocation instruction. English Language \& Literature Teaching, 10(3), 41-66.

Koprowski, M. (2005). Investigating the usefulness of lexical phrases in contemporary coursebooks. ELT Journal, 59(4), 322-32. http://dx.doi.org/ 10.1093/elt/cci061

Krashen, S., \& Scarcella, R. (1978). On routines and patterns in language acquisition and performance. Language Learning, 28(2), 283-300. http://dx.doi.org/10.1111/j.1467-1770.1978.tb00135.x

Laufer, B., \& Waldman, T. (2011). Verb-noun collocations in second language writing: A corpus analysis of learners' English. Language Learning, 61(2), 647-672. http://dx.doi.org/ 10.1111/j.1467-9922.2010.00621.x

Lee, J. K. (2002). The role of formulaic expressions in Korean middle school students' English question formation. (Unpublished doctoral dissertation). Seoul National University, Seoul, Korea.

Levelt, W. (1989). Speaking: From intention to articulation. MA: MIT Press.

Lewis, M. (1997). Implementing the lexical approach: Putting theory into practice. London: Language Teaching Publications.

Littlejohn, A. (1998). The analysis of language teaching materials: Inside the Trojan Horse. In B. Tomlinson (Ed.), Materials development in language teaching (pp.179-211), Cambridge: Cambridge University Press.

Moon, R. (1997). Vocabulary connections: multi-word items in English. In N. Schmitt \& M. McCarthy (Eds.), Vocabulary: Description, acquisition and pedagogy (pp. 40-63). Cambridge: Cambridge University Press.

Myles, F., Hooper, J., \& Mitchell, R. (1998). Rote or rule? Exploring the role of formulaic language in classroom foreign language learning. Language Learning, 48, 323-363. http://dx.doi.org/10.1111/0023-8333.00045 
Nattinger, J., \& DeCarrico, J. (1992). Lexical phrases and language teaching. Oxford: Oxford University Press.

Nesselhauf, N. (2003). The use of collocations by advanced learners of English and some implications for teaching. Applied Linguistics, 24(2), 223-242. http://dx.doi.org/10.1093/applin/24.2.223

Newell, A., \& Rosenbloom, S. (1981). Mechanisms of skill acquisition and the law of practice. In J. Anderson (Ed.) Cognitive skills and their acquisition (pp. 1-55). Hillsdale, NJ: Erlbaum.

Park, S. H. (2003). Lexical collocation use by Korean EFL college learners. (Unpublished master's thesis). Seoul National University, Seoul, Korea.

Pawley, A., \& Syder, F. (1983). Two puzzles for linguistic theory; nativelike selection and nativelike fluency. In J. Richards, \& R. Schmidt (Eds.), Language and communication (pp. 191-226). London: Longman.

Perera, N. S. (2001). The role of prefabricated language in young children's second language acquisition. Bilingual Research Journal, 25. 327-356. http://dx.doi.org/10.1080/15235882.2001.10162797

Schmitt, N. (2008). Review article: Instructed second language vocabulary learning. Language Teaching Research, 12(3), 329-63. http://dx.doi.org/ 10.1177/1362168808089921

Sckehan, P. (1998). A cognitive approach to language learning. Oxford: Oxford University Press.

Serrano, R., Stengers, H., \& Housen, A. (2015). Acquisition of formulaic sequences in intensive and regular EFL programmes. Language Teaching Research, 19(1), 89-106. http://dx.doi.org/ 10.1177/1362168814541748

Sinclair, J. (1987). Collocation: a progress report. In R. Steele, \& T. Threadgold (Eds.), Language topics: essays in honour of Michael Halliday (pp. 319-332) Amsterdam: John Benjamins. http://dx.doi.org/10.1075/z.lt2.68sin

Sinclair, J. (1991). Corpus, concordance, collocation. Oxford: Oxford University Press.

Stengers, H., Boers, F., Housen, A. \& Eyckman, J. (2011). Formulaic sequences and L2 oral proficiency: Does the type of target language influence the association? IRAL, 49(4), 321-39. http://dx.doi.org/10.1515/iral.2011.017

Stringer, J. (1998). Teaching language as oral communication: Everyday life performance in foreign language instruction. Communication Education, 47, 221-223. http://dx.doi.org/10.1080/03634529809379127

Taguchi, N. (2008). Building language blocks in L2 Japanese: Chunking learning and the development of complexity and fluency in spoken production. Foreign Language Annals, 41(1), 132-156. http://dx.doi.org/10.1111/j.1944-9720.2008.tb03283.x

Tomlinson, B. (Ed.). (2011). Materials development in language teaching (2dn ed.), Cambridge: Cambridge University Press.

Wang, J., \& Good, R. (2007). The repetition of collocations in EFL textbooks: A corpus study. Paper presented at The Sixteenth International Symposium and Book Fair on English Teaching in the Republic of China, Taipei.

Weinert, R. (1995). The role of formulaic language in second language acquisition: a review. Applied Linguistics, 16(2), 180-205. http://dx.doi.org/10.1093/applin/16.2.180

Wray, A. (2002). Formulaic language and the lexicon. Cambridge: Cambridge University Press. http://dx.doi.org/10.1017/CBO9780511519772

Wray, A. (2012). What do we (think we) know about formulaic language? An evaluation of the current state of the play. Annual Review of Applied Linguistics, 32, 231-254. http://dx.doi.org/10.1017/S026719051200013X

Wray, A., \& Perkins, M. (2000). The functions of formulaic language: An integrated model. Language and Communication, 20(1), 1-28. http://dx.doi.org/10.1016/S0271-5309(99)00015-4

\section{Notes}

Note 1. In this paper, I use a chunk as an umbrella term to cover all recurrent sequences of words.

Note 2. Developed by Alan Reed, www.textworld.com/scp 


\section{Copyrights}

Copyright for this article is retained by the author(s), with first publication rights granted to the journal.

This is an open-access article distributed under the terms and conditions of the Creative Commons Attribution license (http://creativecommons.org/licenses/by/3.0/). 